\title{
Comparing medical cannabis use in 5 US states: a retrospective database study
}

\author{
V. Kishan Mahabir, Christopher S. Smith*, Christopher Vannabouathong, Jamil J. Merchant and Alisha L. Garibaldi®D
}

\begin{abstract}
Background: US states have been adopting their own medical cannabis laws since 1996. There is substantial variability in the medical cannabis programs between states, and these differences have not been thoroughly investigated in the literature. The objective of the study was to compare medical cannabis patient characteristics across five states to identify differences potentially caused by differing policies surrounding condition eligibility.

Methods: We conducted secondary analyses following a retrospective study of a registry database with data from 33 medical cannabis evaluation clinics in the US, owned and operated by CB2 Insights. This study narrowed the dataset to include patients from five states with the largest samples: Massachusetts $(n=27,892)$, Colorado $(n=16$, 434), Maine $(n=4591)$, Connecticut $(n=2643)$, and Maryland $(n=2403)$ to conduct an in-depth study of the characteristics of patients accessing medical cannabis in these states, including analysis of variance to compare average ages and number of conditions and chi-squared tests to compare proportions of patient characteristics between states.
\end{abstract}

Results: Average ages varied between the states, with the youngest average in Connecticut (42.2) and the oldest in Massachusetts (47.0). Males represented approximately $60 \%$ of the patients with data on gender in each state. The majority of patients in each state had cannabis experience prior to seeking medical certification. Primary medical conditions varied for each state, with chronic pain, anxiety, and back and neck problems topping the list in varying orders for Massachusetts, Maine, and Maryland. Colorado had 78.7\% of patients report chronic pain as their primary condition, and $70.4 \%$ of patients in Connecticut reported post-traumatic stress disorder as their primary medical condition.

Conclusion: This study demonstrated the significant impact that policy has on patients' access to medical cannabis in Massachusetts, Colorado, Maine, Connecticut, and Maryland utilizing real-world data. It highlights how qualifications differ between the five states and brings into question the routes through which patients in states with stricter regulations surrounding eligible conditions choose to seek treatment with cannabis. These patients may turn to alternative treatments, or to the illicit or recreational cannabis markets, where permitted.

Keywords: Medical cannabis regulations, Laws, Chronic pain, Anxiety, Post-traumatic stress disorder, State differences

\section{Background}

Cannabis was added to the United States (US) Controlled Substances Act in 1970, declaring it a Schedule I drug with no accepted medical use and a high potential for abuse (Carliner et al. 2017; Mead 2017).

* Correspondence: christopher.smith@cb2insights.com

CB2 Insights, 5045 Orbitor Dr, Building 11, Suite 300, Mississauga, ON L4W 4Y4, Canada

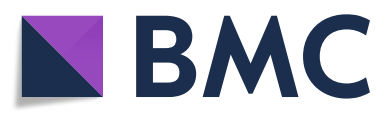

However, there are commonly accepted medicinal effects of cannabis that are largely attributed to delta-9tetrahydrocannabinol (THC) and cannabidiol (CBD), the two cannabinoids that are understood with the greatest scientific rigour (Pertwee 1997; Pertwee et al. 2010). $\mathrm{THC}$ is known for being psychotropic and is the primary concern as regards to cannabis' potential for abuse (Carliner et al. 2017; Mead 2017), whereas CBD is non-

(c) The Author(s). 2021 Open Access This article is licensed under a Creative Commons Attribution 4.0 International License, which permits use, sharing, adaptation, distribution and reproduction in any medium or format, as long as you give appropriate credit to the original author(s) and the source, provide a link to the Creative Commons licence, and indicate if changes were made. The images or other third party material in this article are included in the article's Creative Commons licence, unless indicated otherwise in a credit line to the material. If material is not included in the article's Creative Commons licence and your intended use is not permitted by statutory regulation or exceeds the permitted use, you will need to obtain permission directly from the copyright holder. To view a copy of this licence, visit http://creativecommons.org/licenses/by/4.0/. 
psychotropic and can be accessed legally country-wide when it is derived from hemp with a THC concentration of less than $0.3 \%$ dry weight (FDA Regulation of Cannabis and Cannabis-Derived Products, Including Cannabidiol (CBD) 2020; Shannon et al. 2019).

Although the cannabis plant has been used for centuries in traditional medicine, the laws and policies surrounding its use have been drastically shifting in the US over the last two decades (Alsherbiny and Li 2018; Boehnke et al. 2019a; Cambron et al. 2017; Fairman 2016). Though it remains illegal on a federal level, since the mid-1990s, individual states have been developing their own laws for its use; California was the first state to legalize medical cannabis in 1996 (Legislatures NC of S 2020). Other states have been adopting medical cannabis programs since, and as of October 2020, medical cannabis is legal in 33 states and the District of Columbia, with an additional 12 states and the District of Columbia having legalized recreational cannabis (Boehnke et al. 2019a; DISA Global Solutions 2019). Other states have decriminalized the use of recreational cannabis, whereas some still retain a strict prohibitionist approach both medically and recreationally (Legislatures NC of S 2020; Pacula and Smart 2017).

Among the states with medical cannabis programs, the qualifying medical conditions vary widely and are often updated as the base of evidence surrounding cannabis for medical purposes grows (Pacula and Smart 2017). There are also varying levels of reporting requirements among these states, where some have voluntary registries with minimal data included, and others collect detailed information (Boehnke et al. 2019a; Fairman 2016). The variance between states, coupled with the restrictions in place for conducting cannabis research, has made it increasingly difficult to define and characterize the patients using medical cannabis, and the effectiveness of their treatment.

To add to the medical literature and knowledge surrounding the characteristics of patients accessing medical cannabis in the US, we conducted a retrospective study that included 61,379 medical cannabis patients (Mahabir et al. 2020). These data were extracted from a large medical cannabis patient registry created by CB2 Insights that collects data from 33 medical cannabis evaluation clinics across 12 US states. To further the knowledge and understanding of medical cannabis patients at the state-level, we completed an in-depth analysis comparing patients from the five states with the most patients represented in the dataset: Massachusetts, Colorado, Maine, Connecticut, and Maryland. Highlighting the patient differences between the states is important for understanding the effect qualification regulations are having on patients seeking medical cannabis treatment and the potential limitations of these regulations, which may inform states looking to legalize medical cannabis, or those looking to amend current medical cannabis programs. One of the objectives of this study was to identify topics at a state level for further investigation with respect to current medical cannabis programs.

The included states have varying laws surrounding cannabis, summarized in Table 1. Briefly, some states have legalized both medical and recreational cannabis while others have only legalized medical cannabis. States have also handled the legalization of medical cannabis very differently, with some states allowing practitioners to use their medical judgement in qualifying patients for medical cannabis while others require practitioners to adhere to a strictly defined list of eligible conditions. Finally, the states have differed in the timing of their cannabis laws. There are clear differences between the regulations in these states, and the primary objective of this study was to investigate how these regulations, particularly surrounding eligible conditions, may impact the patients who are choosing to seek treatment with medical cannabis. These data were analyzed to answer the following questions:

1. How do key demographic characteristics differ between patients accessing medical cannabis in the five states?

2. How do the primary conditions reported differ between patients in the five states?

3. Are reported primary conditions similar within states with similar qualifying conditions?

4. How does patient income compare to the state median within each state?

\section{Methods}

This was a retrospective database study of patients seeking medical cannabis certification in the US. Data were extracted from the database software utilized in CB2 Insights' clinical network. CB2 Insights operates one of the largest collections of medical cannabis evaluation clinics in the US, collectively assessing approximately 100,000 patients per year seeking access to medical cannabis, using a single and consistent software that contributes data to a patient registry. These 33 independent clinics are not connected to dispensaries or producers of medical cannabis and are situated across 12 states (number of clinics): Colorado (6), Connecticut (1), Delaware (2), Illinois (1), Maine (1), Maryland (1), Massachusetts (10), Missouri (1), New Jersey (5), New York (1), Rhode Island (2), and Pennsylvania (2), Colorado (6), Connecticut (1), Delaware (2), Illinois (1), Maine (1), Maryland (1), Massachusetts (10),Missouri (1), New Jersey (5), New York (1), Rhode Island (2), and Pennsylvania (2). Patients access these clinics by physician-referral or selfreferral through word of mouth, community out-reach, 
Table 1 Qualifying conditions for patients seeking medical cannabis in Massachusetts, Colorado, Maine, Connecticut, and Maryland

\begin{tabular}{|c|c|}
\hline State & Qualifying condition(s) \\
\hline $\begin{array}{l}\text { Massachusetts (The } 191 \text { st General Court of The } \\
\text { Commonwealth of Massachusetts 2020) } \\
\text { Medically legal: } 2012 \text { (late adopter) } \\
\text { Recreationally legal: } 2016\end{array}$ & $\begin{array}{l}\text { Debilitating medical conditions: cancer, glaucoma, positive status for human } \\
\text { immunodeficiency virus, acquired immune deficiency syndrome (AIDS), hepatitis C, } \\
\text { amyotrophic lateral sclerosis (ALS), Crohn's disease, Parkinson's disease, multiple sclerosis } \\
\text { and other conditions as determined in writing by a qualifying patient's physician. }\end{array}$ \\
\hline
\end{tabular}

Colorado (Colorado - Official State Web Portal 2020) Medically legal: 2000

(early adopter)

Recreationally legal: 2012

Maine (128th Maine Legislature 2020)

Medically legal: 1999

(early adopter)

Recreationally legal: 2016

\section{Connecticut (Connecticut State Department of} Consumer Protection 2020)

Medically legal: 2012

(late adopter)

Decriminalized: 2011
Debilitating medical conditions: cancer, glaucoma, HIV/AIDS, cachexia, persistent muscle spasms, seizures, severe nausea, and severe (chronic) pain.

Disabling medical conditions: post-traumatic stress disorder (PTSD), autism spectrum disorder, and any condition for which a physician could prescribe an opioid.

In the medical provider's professional opinion, a qualifying patient is likely to receive therapeutic benefit from the medical use of marijuana to treat or alleviate the patient's debilitating medical condition.

Adult medical conditions: cancer, glaucoma, HIV/AIDS, Parkinson's disease, multiple sclerosis, damage to nervous tissue of the spinal cord with objective neurological indication of intractable spasticity, epilepsy, cachexia, wasting syndrome, Crohn's disease, post-traumatic stress disorder, sickle cell disease, post laminectomy syndrome with chronic radiculopathy, severe psoriasis and psoriatic arthritis, amyotrophic lateral sclerosis, ulcerative colitis, complex regional pain syndrome Type 1 and Type II, cerebral palsy, cystic fibrosis, irreversible spinal cord injury with objective neurological indication of intractable spasticity, terminal illness requiring end-of-life care, uncontrolled intractable seizure disorder, spasticity or neuropathic pain associated with fibromyalgia, severe rheumatoid arthritis, post herpetic neuralgia, hydrocephalus with intractable headache, intractable headache syndromes, neuropathic facial pain, muscular dystrophy, osteogenesis imperfecta, chronic neuropathic pain associated with degenerative spinal disorders, interstitial cystitis, MALS Syndrome (median arcuate ligament syndrome), vulvodynia and vulvar burning, intractable neuropathic pain that is unresponsive to standard medical treatments, and Tourette syndrome.

Cachexia, anorexia, wasting syndrome, severe or chronic pain, severe nausea, seizures, severe or persistent muscle spasms, glaucoma, post-traumatic stress disorder (PTSD), or another chronic medical condition which is severe and for which other treatments have been ineffective.

\author{
Medically (Natalie $n$. \\ (late adopter) \\ Decriminalized: 2014
}

state, current as of August 2020, as well as the year legalization laws were passed for medical

Table 1 summarizes the medical can
cannabis and recreational cannabis

and marketing. Over $95 \%$ of data were collected via faceto-face interview, with the remaining collected via telemedicine. Patients presenting to any of the clinics are required to complete the same baseline information upon intake, including demographic, medical, and therapeutic information; however, certain characteristics such as race and gender were not made mandatory initially, and are not reported for all patients. Baseline questions include patient-reported tobacco smoking and alcohol use, current or past substance abuse of drugs and/or alcohol, use of illicit (illegal) drugs, medication use, and nonpharmacologic therapies. Medication use is an openended question that may be completed by transcribing a medication list into the software, which leaves room for errors and may be a limitation of the data. All patients indicate their primary reason for seeking access to medical cannabis (their qualifying condition) and are asked to report all comorbid conditions for which they are also seeking medical cannabis. Patients are required to provide supporting documentation of their medical histories and relevant conditions for review and verification, in the form of medical records or a letter from another physician. Review of medical documentation, in combination with a medical evaluation by a state-authorized physician or nurse practitioner, is used to confirm their qualification for medical cannabis within their respective state.

Advarra Institutional Review Board (IRB) reviewed the protocol for these publications and determined it to be exempt from IRB oversight (Pro00042652) as the study had minimal risk, patient identifiers were not included in data exports, and it did not require direct patient contact. Data were exported for 62,145 patients who were seen for their initial assessment between November 18, 2018 (when the technology and standardized protocol were introduced into the clinics) and March 18, 2020. Data were exported without any patient identifiers to ensure patient anonymity. Eligibility criteria were applied to the dataset, and the following patients were removed: 1) 77 patients without a valid date of birth; 2) 78 patients younger than 18; and 3) 611 patients without a primary medical condition reported. To further investigate the differences in demographic, socioeconomic, and medical characteristics of patients accessing medical cannabis in different states, we narrowed our dataset to include the five states with the largest number of registry patients. Patients from Massachusetts (Burlington, Danvers, Fall Rivers, Northampton, Pittsfield, Seekonk, Stoughton, Waltham, Worcester, Yarmouth Port), Colorado (Broomfield, Colorado Springs, Denver, Pueblo), Maine 
(Bangor), Connecticut (Hartford), and Maryland (Columbia, Baltimore) remained in the dataset for further analysis, and patients from Delaware, Illinois, Missouri, New Jersey, New York, Rhode Island, and Pennsylvania were removed.

Data from the database software utilized in CB2 Insights' clinical network were also merged with US tax data, which provides tabulations of income tax data by ZIP code in order to estimate household income based on individual patients' ZIP codes. Median household income values from the 2018 dataset purchased from Cubit Planning Inc. were used (US Income Statistics 2020). Cubit Planning Inc. summarizes the most current income statistics from the US Census Bureau.

States were classified as early medical cannabis adopters (2000 and earlier) (Maine (1999) and Colorado (2000)) or late adopters (Connecticut (2012), Massachusetts (2012), and Maryland (2014)), recreationally legal (Colorado, Massachusetts, and Maine), or decriminalized (Connecticut and Maryland), as summarized in Table 1.

The final dataset was analyzed using RStudio (Boston, MA). The analyses were completed to investigate differences in demographic, socioeconomic, and medical characteristics of patients between the five states. Descriptive statistics, expressed as a mean (standard deviation (SD)) or median (interquartile range (IQR)), were used as appropriate for continuous variables, and number (percent) for categorical variables to summarize information. $T$ tests were conducted when comparing means between two groups, chi-squared tests when comparing proportions, and an analysis of variance (ANOVAs) to compare means of more than two groups using Tukey's honestly significant difference post-hoc test. All tests were completed with a significance level of 0.05. $P$ values less than 0.001 were expressed as $p<0.001$.

\section{Results}

\section{Demographic characteristics}

There were 61,379 patients included in the original analysis. For the purposes of this study, patients from nine states were removed, leaving 53,963 patients from five states: Massachusetts $(n=27,892)$, Colorado $(n=16$, $434)$, Maine $(n=4591)$, Connecticut $(n=2643)$, and Maryland $(n=2403)$ (Supplemental Material, Figure 1). The average age across the five states varied significantly $(p<0.001)$ (Table 2). The youngest average age was reported in Connecticut (42.2, SD = 14.4) and the oldest in Massachusetts $(47.0, \mathrm{SD}=15.7)$. Males represented approximately $60 \%$ of the patients across the entire sample of patients. The proportion of males in Colorado and Maine were significantly larger than the other states $(p<$ 0.001 ) at $61.1 \%$ and $60.9 \%$, respectively, compared to proportions in Connecticut, Massachusetts, and Maryland at $58.5 \%, 58.4 \%$, and $58.8 \%$, respectively. The average age of females was older than males in each state, but the difference was only significant in Colorado, Massachusetts, and Maine (45.1 vs 42.2, $p<0.001 ; 48.9$ vs $46.2, p<0.001$; and 47.0 vs $45.6, p=0.0036$, respectively). Of the patients with race information reported, White individuals represented the majority in each state, ranging from $68.2 \%$ in Maryland to $96.1 \%$ in Maine. There were significant differences in reported tobacco smoking, alcohol use, and substance abuse between states $(p<0.001)$. Smoking was lowest in Maryland (11.3\%) and highest in Colorado (24.7\%). Alcohol use ranged from $38.5 \%$ in Colorado to $44.7 \%$ in Massachusetts. History of substance abuse was lowest in Colorado (2.3\%) and highest in Connecticut (12.5\%).

The median income varied between the states but trended towards the median income of each state. Patients in Maryland and Maine had household incomes very similar to the state median $(\$ 84,257$ compared to $\$ 83,242$ and $\$ 55,737$ compared to $\$ 55,602$, respectively), whereas the median patient household incomes in Colorado, Connecticut, and Massachusetts were lower than the state median $(\$ 64,251$ compared to $\$ 71,953, \$ 71,961$ compared to $\$ 76,348$ and $\$ 75,480$ compared to $\$ 79,835$, respectively) (Guzman 2020). State income distributions compared to sample patient income distributions are compared in Supplemental Materials Figures 2-6. Each individual state sample followed a distribution similar to the overall state.

\section{Prior cannabis experience}

The majority of patients in each state had cannabis experience prior to seeking medical certification. Maine reported the highest proportion of patients with prior experience at $76.4 \%$, and Maryland reported the lowest at 58.2\%. Prior experience in Connecticut, Massachusetts, and Colorado was reported at $74.1 \%, 72.1 \%$, and $63.6 \%$, respectively. States that were early adopters of medical cannabis had a significantly lower proportion of patients with previous cannabis experience than states that were late adopters $(66.4 \%$ compared to $71.3 \%, p<$ 0.001). States that have legalized recreational cannabis reported a higher percentage of patients with prior experience $(69.7 \%$ compared to $66.5 \%, p<0.001)$.

\section{Medication and non-pharmacologic therapy information}

Connecticut had the largest proportion of patients who reported using at least one prescription medication (52.6\%), whereas Colorado had significantly less $(31.6 \%$, $p<0.001)$. Similarly, Colorado reported the smallest proportion $(8.5 \%)$ of patients taking five or more medications, and Connecticut reported the largest (19.8\%). All states had at least $50 \%$ of patients who reported using a non-pharmacologic therapy. Exercise was the most commonly reported therapy in all states (36.1 to 
Table 2 Sociodemographic and medical characteristics of 53,963 patients seeking medical cannabis certification from CB2 Insights clinics in five states

\begin{tabular}{|c|c|c|c|c|c|c|}
\hline Characteristic & $\begin{array}{l}\text { Massachusetts } \\
n=27,892 \\
\text { mean (SD) or } n \\
(\%)\end{array}$ & $\begin{array}{l}\text { Colorado } \\
n=16,434 \\
\text { mean (SD) or } n \\
(\%)\end{array}$ & $\begin{array}{l}\text { Maine } \\
n=4591 \\
\text { mean (SD) or } n \\
(\%)\end{array}$ & $\begin{array}{l}\text { Connecticut } \\
n=2643 \\
\text { mean (SD) or } n \\
(\%)\end{array}$ & $\begin{array}{l}\text { Maryland } \\
n=2403 \\
\text { mean (SD) or } n \\
(\%)\end{array}$ & $\begin{array}{l}\text { Total } \\
n=61,379 \\
\text { mean (SD) or } \\
\%\end{array}$ \\
\hline Age (years), mean (SD) & $47.0(15.9)$ & $43.3(15.9)$ & $46.2(15.6)$ & $42.2(14.4)$ & $45.7(15.7)$ & $45.5(15.8)$ \\
\hline \multicolumn{7}{|l|}{ Gender } \\
\hline Male & $14,615(52.4 \%)$ & 9,969 (60.7\%) & $2,720(59.2 \%)$ & $1,506(57.0 \%)$ & 1,019 (42.4\%) & $54.8 \%$ \\
\hline Female & $10,413(37.3 \%)$ & $6,353(38.7 \%)$ & $1,746(38.0 \%)$ & $1,067(40.4 \%)$ & 714 (29.7\%) & $37.8 \%$ \\
\hline Non-binary & $12(0.0 \%)$ & $5(0.0 \%)$ & $1(0.0 \%)$ & $6(0.2 \%)$ & $4(0.2 \%)$ & $0.1 \%$ \\
\hline Unknown/unspecified & $2,851(10.2 \%)$ & $107(0.7 \%)$ & $124(2.7 \%)$ & $64(2.4 \%)$ & $666(27.7 \%)$ & $7.3 \%$ \\
\hline Race & $n=11,005$ & $n=12,266$ & $n=1,452$ & $n=1,927$ & $n=654$ & $n=32,275$ \\
\hline White & 10,304 (93.6\%) & $10,372(84.6 \%)$ & 1,396 (96.1\%) & $1,615(83.8 \%)$ & $446(68.2 \%)$ & $87.5 \%$ \\
\hline Black & $451(4.1 \%)$ & $1,169(9.5 \%)$ & $17(1.2 \%)$ & $268(13.9 \%)$ & $184(28.1 \%)$ & $8.5 \%$ \\
\hline Other & $110(1.0 \%)$ & $316(2.6 \%)$ & $20(1.4 \%)$ & $21(1.1 \%)$ & $6(0.9 \%)$ & $1.6 \%$ \\
\hline Asian & $94(0.9 \%)$ & $117(1.0 \%)$ & $7(0.5 \%)$ & $13(0.7 \%)$ & $10(1.5 \%)$ & $0.9 \%$ \\
\hline American Indian/Alaska Native & $9(0.1 \%)$ & $210(1.7 \%)$ & $10(0.7 \%)$ & $6(0.3 \%)$ & $2(0.3 \%)$ & $0.8 \%$ \\
\hline Middle Eastern & $22(0.2 \%)$ & $19(0.2 \%)$ & $0(0.0 \%)$ & $3(0.2 \%)$ & $3(0.5 \%)$ & $0.2 \%$ \\
\hline $\begin{array}{l}\text { Native Hawaiian/other Pacific } \\
\text { Islander }\end{array}$ & $2(0.0 \%)$ & $47(0.4 \%)$ & $2(0.1 \%)$ & $0(0.0 \%)$ & $2(0.3 \%)$ & $0.2 \%$ \\
\hline South East Asian & $13(0.1 \%)$ & $16(0.1 \%)$ & $0(0.0 \%)$ & $1(0.1 \%)$ & $1(0.2 \%)$ & $0.1 \%$ \\
\hline Surrogate household income & $n=25,182$ & $n=15,627$ & $n=4,222$ & $n=2,595$ & $n=1,718$ & $n=56,083$ \\
\hline Median & $\$ 75,480$ & $\$ 64,251$ & $\$ 55,737$ & $\$ 71,961$ & $\$ 84,257$ & $\$ 69,481$ \\
\hline$(\mathrm{QQR})$ & $(\$ 37,785)$ & $(\$ 32,120)$ & $(\$ 19,633)$ & $(\$ 29,852)$ & $(\$ 37,917)$ & $(\$ 35,807)$ \\
\hline \multicolumn{7}{|l|}{ Smoking status ${ }^{\mathrm{a}, \mathrm{b}}$} \\
\hline Smoker & $3,994(14.3 \%)$ & 4,059 (24.7\%) & $1,022(22.3 \%)$ & $638(24.1 \%)$ & $271(11.3 \%)$ & $18.8 \%$ \\
\hline Non-Smoker & $23,897(85.7 \%)$ & $12,375(75.3 \%)$ & $3,569(77.7 \%)$ & $2,005(75.9 \%)$ & 2,132 (88.7\%) & $81.2 \%$ \\
\hline \multicolumn{7}{|l|}{ Alcohol consumption $^{\mathrm{a}, \mathrm{b}}$} \\
\hline Yes & $12,459(44.7 \%)$ & $6,323(38.5 \%)$ & $1,905(41.5 \%)$ & $1,081(40.9 \%)$ & $976(40.6 \%)$ & $42.5 \%$ \\
\hline No & $15,432(55.3 \%)$ & $10,111(61.5 \%)$ & $2,686(58.5 \%)$ & $1,562(59.1 \%)$ & $1,427(59.4 \%)$ & $57.5 \%$ \\
\hline \multicolumn{7}{|l|}{ Previous cannabis experience ${ }^{a, b}$} \\
\hline Yes & $20,118(72.1 \%)$ & $10,450(63.6 \%)$ & 3,509 (76.4\%) & $1,959(74.1 \%)$ & 1,399 (58.2\%) & $66.9 \%$ \\
\hline No & $7,773(27.9 \%)$ & $5,984(36.4 \%)$ & $1,082(23.6 \%)$ & $684(25.9 \%)$ & $1,004(41.8 \%)$ & $33.1 \%$ \\
\hline \multicolumn{7}{|l|}{ Use of non-cannabis illicit drugs } \\
\hline Yes & $95(0.3 \%)$ & $89(0.5 \%)$ & $15(0.3 \%)$ & $12(0.5 \%)$ & $5(0.2 \%)$ & $0.4 \%$ \\
\hline No & $27,796(99.7 \%)$ & $16,345(99.5 \%)$ & $4,576(99.7 \%)$ & $2,631(99.5 \%)$ & 2,398 (99.8\%) & $99.6 \%$ \\
\hline \multicolumn{7}{|l|}{ History of substance abuse ${ }^{a, b}$} \\
\hline Yes & $1,875(6.7 \%)$ & $380(2.3 \%)$ & $296(6.4 \%)$ & $330(12.5 \%)$ & $81(3.4 \%)$ & $5.6 \%$ \\
\hline No & $26.016(93.3 \%)$ & $16,054(97.7 \%)$ & 4,295 (93.6\%) & $2,313(87.5 \%)$ & 2,322 (96.6\%) & $94.4 \%$ \\
\hline \multicolumn{7}{|l|}{ Number of medications $s^{a, b}$} \\
\hline 0 & $14,272(51.2 \%)$ & $11,233(68.4 \%)$ & $2,625(57.2 \%)$ & $1,252(47.4 \%)$ & $1,216(50.6 \%)$ & $55.8 \%$ \\
\hline 1 & 3,780 (13.6\%) & $1,601(9.7 \%)$ & 569 (12.4\%) & $358(13.5 \%)$ & 427 (17.8\%) & $12.8 \%$ \\
\hline 2 & $2,263(8.1 \%)$ & 956 (5.8\%) & 399 (8.7\%) & $210(8.0 \%)$ & 226 (9.4\%) & $7.7 \%$ \\
\hline 3 & $1,683(6.0 \%)$ & 738 (4.5\%) & 244 (5.3\%) & 179 (6.8\%) & $158(6.6 \%)$ & $5.7 \%$ \\
\hline 4 & 1,115 (4.0\%) & 515 (3.1\%) & 167 (3.6\%) & $120(4.5 \%)$ & $124(5.1 \%)$ & $3.9 \%$ \\
\hline $5+$ & 4,779 (17.1\%) & 1,391 (8.5\%) & 587 (12.8\%) & 524 (19.8\%) & 252 (10.5\%) & $14.0 \%$ \\
\hline
\end{tabular}


Table 2 Sociodemographic and medical characteristics of 53,963 patients seeking medical cannabis certification from CB2 Insights clinics in five states (Continued)

\begin{tabular}{|c|c|c|c|c|c|c|}
\hline Characteristic & $\begin{array}{l}\text { Massachusetts } \\
n=27,892 \\
\text { mean (SD) or } n \\
\text { (\%) }\end{array}$ & $\begin{array}{l}\text { Colorado } \\
n=16,434 \\
\text { mean (SD) or } n \\
(\%)\end{array}$ & $\begin{array}{l}\text { Maine } \\
n=4591 \\
\text { mean (SD) or } n \\
(\%)\end{array}$ & $\begin{array}{l}\text { Connecticut } \\
n=2643 \\
\text { mean (SD) or } n \\
(\%)\end{array}$ & $\begin{array}{l}\text { Maryland } \\
n=2403 \\
\text { mean (SD) or } n \\
(\%)\end{array}$ & $\begin{array}{l}\text { Total } \\
n=61,379 \\
\text { mean (SD) or } \\
\%\end{array}$ \\
\hline Average number of medications & $2.2(3.5)$ & $1.2(2.5)$ & $1.7(3.1)$ & $2.5(3.7)$ & $1.7(2.8)$ & $2.1(4.8)$ \\
\hline \multicolumn{7}{|c|}{ Number of non-pharmacologic therapies used } \\
\hline 0 & $10,408(37.3 \%)$ & $7,979(48.6 \%)$ & $1,570(34.2 \%)$ & $997(37.7 \%)$ & $1,065(44.3 \%)$ & $40.6 \%$ \\
\hline 1 & $5,558(19.9 \%)$ & $3,537(21.5 \%)$ & $1,121(24.4 \%)$ & $586(22.2 \%)$ & $487(20.3 \%)$ & $20.9 \%$ \\
\hline 2 & $4,461(16.0 \%)$ & $2,256(13.7 \%)$ & $789(17.2 \%)$ & $388(14.7 \%)$ & $322(13.4 \%)$ & $15.3 \%$ \\
\hline 3 & $3,184(11.4 \%)$ & $1,264(7.7 \%)$ & $503(11.0 \%)$ & $265(10.0 \%)$ & $264(11.0 \%)$ & $10.1 \%$ \\
\hline 4 & $1,904(6.9 \%)$ & $674(4.1 \%)$ & $273(5.9 \%)$ & $181(6.8 \%)$ & $148(6.2 \%)$ & $6.0 \%$ \\
\hline $5+$ & $2,377(8.5 \%)$ & 724 (4.4\%) & $335(7.3 \%)$ & $226(8.6 \%)$ & 117 (4.9\%) & $7.1 \%$ \\
\hline \multicolumn{7}{|l|}{ Non-pharmacologic therapies } \\
\hline Exercise & $12,540(45.0 \%)$ & $5,935(36.1 \%)$ & $2,151(46.9 \%)$ & $1,137(43.0 \%)$ & 935 (38.9\%) & $42.1 \%$ \\
\hline Massage therapy & $6,750(24.2 \%)$ & 2,937 (17.9\%) & $972(21.2 \%)$ & $511(19.3 \%)$ & $466(19.4 \%)$ & $21.6 \%$ \\
\hline Chiropractor & $5,540(19.9 \%)$ & $2,272(13.8 \%)$ & $1,050(22.9 \%)$ & $362(13.7 \%)$ & $349(14.5 \%)$ & $18.0 \%$ \\
\hline Mental health counselling & 6,117 (21.9\%) & $1,579(9.6 \%)$ & $864(18.8 \%)$ & $757(28.6 \%)$ & $421(17.5 \%)$ & $18.3 \%$ \\
\hline Physiotherapy & $1,342(4.8 \%)$ & $1,270(7.7 \%)$ & $215(4.7 \%)$ & $102(3.9 \%)$ & $100(4.2 \%)$ & $5.5 \%$ \\
\hline $\begin{array}{l}\text { Mindfulness-based cognitive } \\
\text { therapy }\end{array}$ & $2,760(9.9 \%)$ & $1,111(6.8 \%)$ & $251(5.5 \%)$ & $295(11.2 \%)$ & $175(7.3 \%)$ & $8.4 \%$ \\
\hline Aromatherapy & $1,669(6.0 \%)$ & $1,015(6.2 \%)$ & $293(6.4 \%)$ & $211(8.0 \%)$ & 139 (5.8\%) & $6.3 \%$ \\
\hline Homeopathic medicine & $1,467(5.3 \%)$ & $793(4.8 \%)$ & $278(6.1 \%)$ & $123(4.7 \%)$ & $92(3.8 \%)$ & $5.2 \%$ \\
\hline Acupuncture & 3,309 (11.9\%) & 769 (4.7\%) & $503(11.0 \%)$ & $206(7.8 \%)$ & $243(10.1 \%)$ & $9.2 \%$ \\
\hline $\begin{array}{l}\text { Cognitive behavioural therapy } \\
\text { (CBT) }\end{array}$ & $1,885(6.8 \%)$ & $478(2.9 \%)$ & $270(5.9 \%)$ & $213(8.1 \%)$ & $115(4.8 \%)$ & $5.7 \%$ \\
\hline Naturopathic medicine & $860(3.1 \%)$ & $403(2.5 \%)$ & 149 (3.2\%) & $104(3.9 \%)$ & $49(2.0 \%)$ & $2.9 \%$ \\
\hline Reiki & $1,380(4.9 \%)$ & $308(1.9 \%)$ & $205(4.5 \%)$ & $113(4.3 \%)$ & $71(3.0 \%)$ & $3.8 \%$ \\
\hline Addictions counselling & $602(2.2 \%)$ & $137(0.8 \%)$ & $131(2.9 \%)$ & $115(4.4 \%)$ & $35(1.5 \%)$ & $1.9 \%$ \\
\hline Acudetox & $19(0.1 \%)$ & $29(0.2 \%)$ & $7(0.2 \%)$ & $4(0.2 \%)$ & $6(0.2 \%)$ & $0.1 \%$ \\
\hline Other & $42(0.1 \%)$ & $11(0.1 \%)$ & $18(0.4 \%)$ & $8(0.3 \%)$ & $8(0.3 \%)$ & $0.4 \%$ \\
\hline \multicolumn{7}{|l|}{ Number of comorbid conditions } \\
\hline 0 & $2,206(7.9 \%)$ & $6,263(38.1 \%)$ & $294(6.4 \%)$ & $212(8.0 \%)$ & $213(8.9 \%)$ & $17.6 \%$ \\
\hline 1 & $5,719(20.5 \%)$ & $5,548(33.8 \%)$ & $940(20.5 \%)$ & $429(16.2 \%)$ & $663(27.6 \%)$ & $26.0 \%$ \\
\hline 2 & $4,935(17.7 \%)$ & $2,540(15.5 \%)$ & $991(21.6 \%)$ & $402(15.2 \%)$ & 459 (19.1\%) & $16.1 \%$ \\
\hline 3 & 4,028 (14.4\%) & 1,183 (7.2\%) & 700 (15.2\%) & 370 (14.0\%) & 415 (17.3\%) & $11.9 \%$ \\
\hline 4 & 3,276 (11.8\%) & 548 (3.3\%) & $531(11.6 \%)$ & $310(11.7 \%)$ & 253 (10.5\%) & $9.0 \%$ \\
\hline $5+$ & 7,728 (27.7\%) & 352 (2.1\%) & 1,135 (24.7\%) & 920 (34.9\%) & 400 (16.6\%) & $19.4 \%$ \\
\hline $\begin{array}{l}\text { Total number of conditions, mean } \\
(\mathrm{SD})^{\mathrm{a}, \mathrm{b}}\end{array}$ & $4.3(2.8)$ & $2.1(1.3)$ & $4.1(2.6)$ & $4.8(3.1)$ & $3.6(2.1)$ & $3.7(2.6)$ \\
\hline
\end{tabular}

Table 2 summarizes key patient characteristics of patients seeking medical cannabis access at CB2 Insights clinics between November 2018 and March 2020 across five states. The total column includes all 61,379 patients included in the initial study for comparison, including patients from 12 states (Mahabir et al. 2020). Total number of conditions refers to a count of the number of comorbid conditions plus one for the patients' primary condition. SD = standard deviation

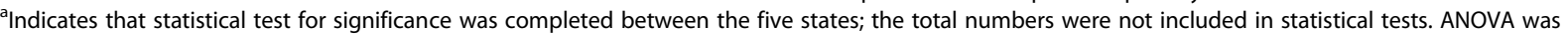
conducted for average age and average number of conditions between states. Chi-squared tests were conducted for differences in proportions between states

${ }^{b}$ Indicates that statistical test was significant, and the characteristic was significantly different between states 
46.9\%), followed by massage therapy in Massachusetts, Colorado, and Maryland (24.2\%, 17.9\%, and 19.4\%, respectively), chiropractor in Maine (22.9\%), and mental health counselling in Connecticut (28.6\%).

\section{Qualifying medical conditions and comorbid conditions}

The reported primary conditions of patients varied widely between states (Table 3). Massachusetts, Maine, and Maryland had a similar spread of proportions of primary medical conditions, with 5 or 6 conditions in each state being reported by $5 \%$ or more of patients (Fig. 1). In each of these states, chronic pain $(19.4 \%, 35.9 \%$, $23.7 \%)$, anxiety $(21.7 \%, 12.7 \%, 20.3 \%)$, and back and neck problems $(9.8 \%, 12.9 \%, 11.4 \%)$ were the top 3 medical conditions reported, although the order varied in each state. The distribution of proportions in Colorado and Connecticut was significantly different than the former three states. In Colorado, $78.7 \%$ of patients reported chronic pain as their primary medical condition, followed by muscle spasms at $4.7 \%$. In Connecticut, $70.4 \%$ of patients reported PTSD as their primary medical condition, with spinal cord injury/disease reported second most often (7.3\%).

Anxiety was the most commonly reported comorbid condition in Massachusetts, Maine, Connecticut, and Maryland (35.2\%, 33.6\%, 58.0\%, 29.5\%). Back and neck problems, depression, insomnia, chronic pain, and stress were also all reported by at least $20 \%$ of patients in each of these four states as well. Fewer than $10 \%$ of patients in each of these four states did not report having a comorbid condition. Contrarily, almost $40 \%$ of patients in Colorado did not report a comorbid condition and, of those who did, muscle spasms were reported by most patients (13.0\%), followed by chronic nausea (10.1\%) and back and neck problems (10.0\%).

The total number of conditions reported varied significantly between states $(p<0.001)$ (Table 2$)$. Patients in Connecticut reported the highest number of average conditions $(4.8, \mathrm{SD}=3.1)$, whereas patients in Colorado reported the lowest $(2.1, \mathrm{SD}=1.3)$.

\section{Discussion}

This retrospective study provided a detailed description of cannabis users across five US states: Massachusetts, Colorado, Maine, Connecticut, and Maryland. Patient demographics as well as medical characteristics varied significantly between the states. Males consistently represented a higher proportion of patients in each state, and females were on average older than males within each state, but this difference was not significant in Connecticut or Maryland. At a high level, relatively similar findings have been reported in other studies, with males accessing medical cannabis more than females, and an average age of patients in their forties (Eurich et al. 2019; Fairman 2016; Piper et al. 2017a; Sexton et al. 2016).

Reviewing the race breakdown of patients accessing medical cannabis at our clinics in each state, the distributions were similar when compared to the overall racial breakdown within each state overall, with some variation. White individuals were slightly underrepresented in Connecticut and Colorado, and overrepresented in Maryland and Massachusetts (U.S. Census Bureau QuickFacts: United States 2020). Black individuals were adequately represented when compared to state demographics in Connecticut, Maine, and Maryland, but underrepresented in Massachusetts and overrepresented in Colorado. We hypothesize that the varying representation in Massachusetts and Colorado is due specifically to the locations of the clinics, as they are in areas with a proportion of Black individuals lower than the state average in Massachusetts, and higher in Colorado. This state-by-state breakdown gives an interesting perspective on race and medical cannabis use. White individuals are often the largest race group reported accessing medical cannabis in studies; however, this study demonstrates that race representation may be proportional to that within the jurisdiction.

The median estimated household incomes for patients in the registry from Massachusetts, Colorado, and Connecticut were lower than the state medians (Bureau UC. U.S n.d.), which is in line with similar studies that report that medical cannabis users tend to have a lower income than the median (Reiman 2007; Sexton et al. 2016). Contrarily, patients in Maryland and Maine had estimated household incomes very similar to the state median. It is important to highlight how reporting income as a whole for this sample would have skewed these results drastically: the median household income of the sample is $\$ 68$, 874 , which is higher than the US median of $\$ 61,937$ (Bureau UC. U.S n.d.). Reporting by state gives a much clearer picture of the sociodemographic characteristics of medical cannabis users. Further, distributions for each sample roughly mirrored the state-level distribution, indicating that income may not be a contributing factor to patients seeking medical cannabis.

All states reported a higher percentage of patients with prior experience than the US average for lifetime cannabis use, which was $45.3 \%$ in 2018 (2018 NSDUH Detailed Tables | CBHSQ Data 2020). We hypothesized that prior experience would be higher in states that were early adopters of medical cannabis, but the study results did not support this. Stigma may be lower in states where medical cannabis has been legal for a substantial period of time, leading to inexperienced patients being more willing to seek proper medical treatment with cannabis initially, rather than self-treating. However, prior use was higher in states with legalized recreational 
Table 3 Summary of primary and comorbid conditions reported by 53,963 patients seeking medical cannabis certification across five states

\begin{tabular}{|c|c|c|c|c|c|c|c|c|c|c|c|}
\hline \multirow{2}{*}{$\begin{array}{l}\text { Condition } \\
\text { Primary condition }\end{array}$} & \multicolumn{2}{|c|}{$\begin{array}{l}\text { Massachusetts } \\
n=27,892 \\
n(\%)\end{array}$} & \multicolumn{2}{|c|}{$\begin{array}{l}\text { Colorado } \\
n=16,434 \\
n(\%)\end{array}$} & \multicolumn{2}{|c|}{$\begin{array}{l}\text { Maine } \\
n=4591 \\
n(\%)\end{array}$} & \multicolumn{2}{|c|}{$\begin{array}{l}\text { Connecticut } \\
n=2643 \\
n(\%)\end{array}$} & \multicolumn{2}{|c|}{$\begin{array}{l}\text { Maryland } \\
n=2403 \\
n(\%)\end{array}$} & \multirow[t]{2}{*}{$\begin{array}{l}\text { Total } \\
n=61,379 \\
\%\end{array}$} \\
\hline & & & & & & & & & & & \\
\hline Chronic pain & 5407 & $(19.4 \%)$ & 12926 & $(78.7 \%)$ & 1646 & (35.9\%) & 42 & $(1.6 \%)$ & 569 & $(23.7 \%)$ & $38.8 \%$ \\
\hline Anxiety & 6062 & $(21.7 \%)$ & 5 & $(<0.1 \%)$ & 581 & $(12.7 \%)$ & 9 & $(0.3 \%)$ & 487 & (20.3\%) & $13.5 \%$ \\
\hline Post-traumatic stress disorder & 1439 & $(5.2 \%)$ & 456 & $(2.8 \%)$ & 323 & $(7.0 \%)$ & 1860 & $(70.4 \%)$ & 126 & $(5.2 \%)$ & $8.4 \%$ \\
\hline Back and neck problems & 2737 & $(9.8 \%)$ & 22 & $(0.1 \%)$ & 590 & $(12.9 \%)$ & 24 & $(0.9 \%)$ & 273 & (11.4\%) & $6.5 \%$ \\
\hline Arthritis & 1785 & $(6.4 \%)$ & 14 & $(0.1 \%)$ & 232 & $(5.1 \%)$ & 44 & $(1.7 \%)$ & 142 & $(5.9 \%)$ & $3.9 \%$ \\
\hline Insomnia & 1811 & $(6.5 \%)$ & 1 & $(0.0 \%)$ & 169 & $(3.7 \%)$ & 0 & $(0.0 \%)$ & 76 & $(3.2 \%)$ & $3.4 \%$ \\
\hline Cancer-related pain & 752 & $(2.7 \%)$ & 447 & $(2.7 \%)$ & 84 & $(1.8 \%)$ & 98 & $(3.7 \%)$ & 48 & $(2.0 \%)$ & $2.7 \%$ \\
\hline Depression & 1050 & $(3.8 \%)$ & 0 & $(0.0 \%)$ & 58 & $(1.3 \%)$ & 0 & $(0.0 \%)$ & 102 & $(4.2 \%)$ & $2.0 \%$ \\
\hline Migraines & 810 & $(2.9 \%)$ & 26 & $(0.2 \%)$ & 136 & $(3.0 \%)$ & 36 & $(1.4 \%)$ & 54 & $(2.2 \%)$ & $2.0 \%$ \\
\hline Muscle spasms & 148 & $(0.5 \%)$ & 780 & $(4.7 \%)$ & 32 & $(0.7 \%)$ & 0 & $(0.0 \%)$ & 26 & $(1.1 \%)$ & $1.7 \%$ \\
\hline ADD/ADHD & 866 & $(3.1 \%)$ & 0 & $(0.0 \%)$ & 71 & $(1.5 \%)$ & 0 & $(0.0 \%)$ & 39 & $(1.6 \%)$ & $1.6 \%$ \\
\hline Chronic nausea & 248 & $(0.9 \%)$ & 546 & $(3.3 \%)$ & 60 & $(1.3 \%)$ & 0 & $(0.0 \%)$ & 16 & $(0.7 \%)$ & $1.5 \%$ \\
\hline Fibromyalgia & 448 & $(1.6 \%)$ & 14 & $(0.1 \%)$ & 57 & $(1.2 \%)$ & 53 & $(2.0 \%)$ & 28 & $(1.2 \%)$ & $1.2 \%$ \\
\hline Headaches & 292 & $(1.0 \%)$ & 242 & $(1.5 \%)$ & 94 & $(2.0 \%)$ & 29 & $(1.1 \%)$ & 15 & $(0.6 \%)$ & $1.2 \%$ \\
\hline Spinal cord injury/disease & 263 & $(0.9 \%)$ & 0 & $(0.0 \%)$ & 15 & $(0.3 \%)$ & 192 & $(7.3 \%)$ & 22 & $(0.9 \%)$ & $0.9 \%$ \\
\hline Other & 3774 & $(13.5 \%)$ & 955 & $(5.8 \%)$ & 443 & $(9.6 \%)$ & 256 & $(9.7 \%)$ & 380 & (15.8\%) & $10.7 \%$ \\
\hline \multicolumn{12}{|l|}{ Comorbid Conditions } \\
\hline Anxiety & 9815 & $(35.2 \%)$ & 1226 & $(7.5 \%)$ & 1543 & (33.6\%) & 1534 & $(58.0 \%)$ & 710 & $(29.5 \%)$ & $28.3 \%$ \\
\hline Back and neck problems & 7858 & $(28.2 \%)$ & 1642 & $(10.0 \%)$ & 1323 & $(28.8 \%)$ & 807 & $(30.5 \%)$ & 564 & (23.5\%) & $23.7 \%$ \\
\hline Depression & 8290 & $(29.7 \%)$ & 481 & $(2.9 \%)$ & 1059 & (23.1\%) & 1014 & (38.4\%) & 560 & (23.3\%) & $21.9 \%$ \\
\hline Insomnia & 9442 & $(33.9 \%)$ & 740 & $(4.5 \%)$ & 1157 & $(25.2 \%)$ & 782 & $(29.6 \%)$ & 491 & (20.4\%) & $23.2 \%$ \\
\hline Chronic pain & 6227 & $(22.3 \%)$ & 1072 & $(6.5 \%)$ & 1314 & $(28.6 \%)$ & 653 & $(24.7 \%)$ & 584 & (24.3\%) & $18.2 \%$ \\
\hline Stress & 7171 & $(25.7 \%)$ & 73 & $(0.4 \%)$ & 913 & (19.9\%) & 947 & $(35.8 \%)$ & 571 & $(23.8 \%)$ & $11.2 \%$ \\
\hline Headaches & 4569 & $(16.4 \%)$ & 1339 & $(8.1 \%)$ & 756 & $(16.5 \%)$ & 487 & $(18.4 \%)$ & 277 & (11.5\%) & $14.2 \%$ \\
\hline Arthritis & 5013 & $(18.0 \%)$ & 700 & $(4.3 \%)$ & 767 & $(16.7 \%)$ & 452 & $(17.1 \%)$ & 286 & (11.9\%) & $14.0 \%$ \\
\hline Muscle spasms & 3234 & $(11.6 \%)$ & 2141 & $(13.0 \%)$ & 668 & $(14.6 \%)$ & 331 & $(12.5 \%)$ & 277 & $(11.5 \%)$ & $12.8 \%$ \\
\hline Migraines & 3508 & $(12.6 \%)$ & 692 & $(4.2 \%)$ & 392 & $(8.5 \%)$ & 362 & $(13.7 \%)$ & 189 & $(7.9 \%)$ & $9.9 \%$ \\
\hline Post-traumatic stress disorder & 3265 & $(11.7 \%)$ & 1257 & $(7.6 \%)$ & 618 & $(13.5 \%)$ & 114 & $(4.3 \%)$ & 201 & $(8.4 \%)$ & $10.0 \%$ \\
\hline ADD/ADHD & 2855 & $(10.2 \%)$ & 88 & $(0.5 \%)$ & 366 & $(8.0 \%)$ & 377 & $(14.3 \%)$ & 216 & $(9.0 \%)$ & $7.5 \%$ \\
\hline Mood disorders & 2222 & $(8.0 \%)$ & 30 & $(0.2 \%)$ & 261 & $(5.7 \%)$ & 308 & $(11.7 \%)$ & 140 & $(5.8 \%)$ & $6.0 \%$ \\
\hline Chronic nausea & 1544 & $(5.5 \%)$ & 1665 & $(10.1 \%)$ & 350 & $(7.6 \%)$ & 0 & $(0.0 \%)$ & 77 & $(3.2 \%)$ & $7.2 \%$ \\
\hline Neuropathic pain & 1660 & $(6.0 \%)$ & 165 & $(1.0 \%)$ & 253 & $(5.5 \%)$ & 200 & $(7.6 \%)$ & 96 & $(4.0 \%)$ & $4.8 \%$ \\
\hline Irritable bowel syndrome & 1698 & $(6.1 \%)$ & 82 & $(0.5 \%)$ & 292 & $(6.4 \%)$ & 197 & $(7.5 \%)$ & 83 & $(3.5 \%)$ & $4.6 \%$ \\
\hline Appetite stimulation & 1875 & $(6.7 \%)$ & 112 & $(0.7 \%)$ & 256 & $(5.6 \%)$ & 157 & $(5.9 \%)$ & 102 & $(4.2 \%)$ & $4.7 \%$ \\
\hline Fibromyalgia & 967 & $(3.5 \%)$ & 189 & $(1.2 \%)$ & 173 & $(3.8 \%)$ & 83 & (3.1\%) & 48 & $(2.0 \%)$ & $2.9 \%$ \\
\hline Spinal cord injury & 928 & $(3.3 \%)$ & 27 & $(0.2 \%)$ & 131 & $(2.9 \%)$ & 105 & $(4.0 \%)$ & 63 & $(2.6 \%)$ & $2.7 \%$ \\
\hline Obsessive compulsive behavior & 904 & $(3.2 \%)$ & 11 & $(0.1 \%)$ & 89 & $(1.9 \%)$ & 132 & (5.0\%) & 45 & (1.9\%) & $2.3 \%$ \\
\hline
\end{tabular}

Table 3 provides a summary of the reported primary and comorbid conditions of patients seeking medical cannabis access at CB2 Insights clinics between November 2018 and March 2020 across five states. The total column includes all 61,379 patients included in the initial study for comparison, including patients from 12 states (Mahabir et al. 2020). Patients could only report one primary condition. All conditions that represented at least $2.0 \%$ of the sample in one state are listed, the remaining are grouped under "other". Patients could report multiple comorbid conditions, but not the same comorbid condition as their primary. The top 20 are reported in the table. $A D D=$ attention deficit disorder; $A D H D=$ attention deficit hyperactivity disorder 


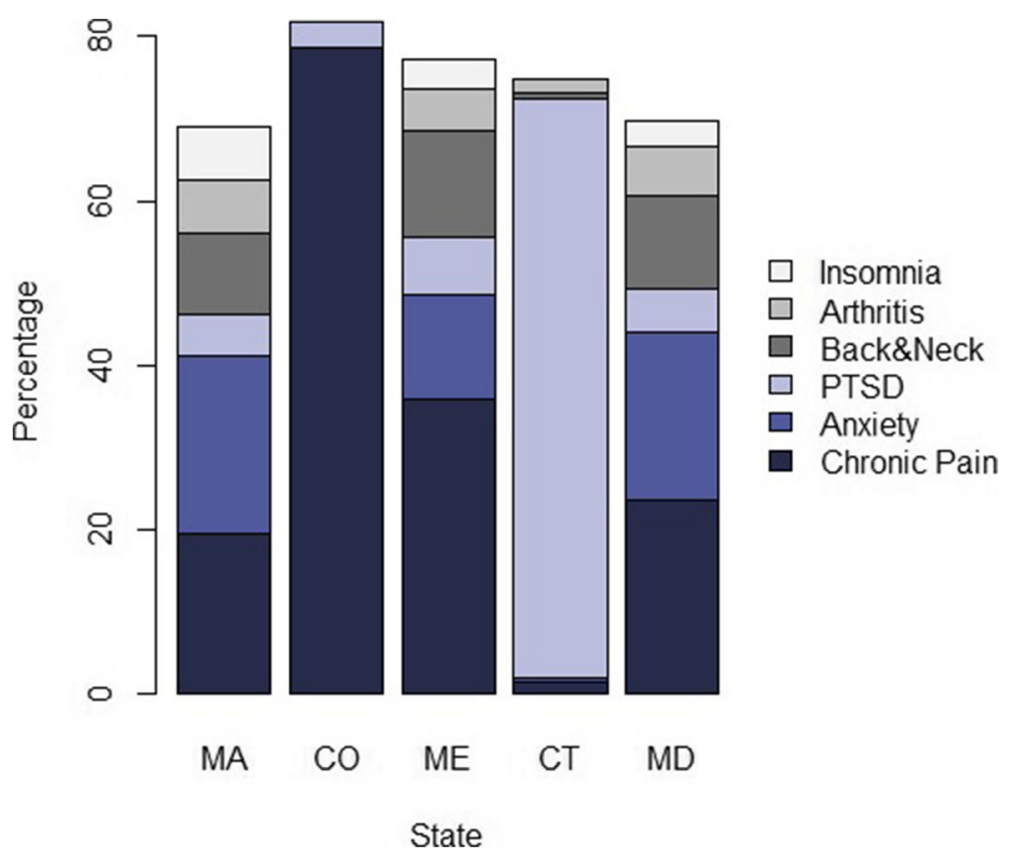

Fig. 1 Top 6 primary qualifying conditions reported by medical cannabis patients, by state. PTSD = post-traumatic stress disorder; MA = Massachusetts; $\mathrm{CO}=$ Colorado; $\mathrm{ME}=$ Maine; $\mathrm{CT}=$ Connecticut; $\mathrm{MD}=$ Maryland

cannabis, although the proportions varied between these states. This finding is contrary to findings that legalizing cannabis does not necessarily increase use, although the evidence surrounding this is inconsistent (Cerdá et al. 2020; Cerdá et al. 2017; Cerdá et al. 2011; Gorman and Huber 2007; Leyton 2019; Marijuana Decriminalization and Its Impact on Use - NORML - Working to Reform Marijuana Laws 2020). The process by which patients choose to seek treatment with medical cannabis merits further investigation, as an understanding of this may help encourage patients who would like to use cannabis medically to seek guidance and oversight by a medical team as their first option.

Following our first study in which chronic pain was the clear frontrunner for patients' primary medical condition, the same result was expected when looking at individual states, but this was not the case. The impact of the differences between state qualifying conditions is highlighted well by our results. In Massachusetts, Maine, and Maryland, the distributions of primary conditions were similar. Within each of these states guidelines' for eligible qualifying conditions, patients with other conditions for which the practitioner believes medical cannabis may be an effective treatment may be granted certification (128th Maine Legislature 2020; Natalie n.d.; The 191st General Court of The Commonwealth of Massachusetts 2020). Massachusetts and Maryland have a short list of medical conditions included with the aforementioned statement, whereas Maine does not provide a list (Table 1) (128th Maine
Legislature 2020; Natalie n.d.; The 191st General Court of The Commonwealth of Massachusetts 2020). Interestingly, none of the top three primary medical conditions reported in Massachusetts or Maryland (chronic pain, anxiety, back and neck problems) appear on the short lists. We hypothesize that allowing practitioners to use their medical judgement when qualifying patients may provide patients greater access to medical cannabis within these states and may provide a clearer picture of the true conditions for which patients seek medical cannabis. The breakdown of primary medical conditions reported in Colorado and Connecticut followed much different patterns, and we again hypothesize that this is a direct result of the statedefined qualifying conditions.

In Colorado, patients may qualify based on a limited number of conditions, or any condition for which a physician could prescribe an opioid (Colorado - Official State Web Portal 2020). The latter is heavily represented in the patient sample from Colorado, as almost $80 \%$ of patients reported chronic pain as their primary medical condition (Boehnke et al. 2016; Boehnke et al. 2019b; Lucas et al. 2019; Piper et al. 2017b). The medical conditions with the highest proportion of patients following chronic pain were muscle spasms and chronic nausea, which are explicitly stated in the guidelines to be qualifying conditions.

Connecticut has a lengthy list of qualifying conditions, but despite this list, the majority of patients reported PTSD as their primary medical condition (Connecticut 
State Department of Consumer Protection 2020). There is not a clear indication as to why PTSD is reported by the majority of patients accessing medical cannabis in Connecticut, compared to the other states in which 10$20 \%$ of patients reported PTSD as a primary or comorbid condition, which aligns with an article indicating that $23 \%$ of patients seeking medical cannabis for the first time screen positive for lifetime PTSD (Bohnert et al. 2014). We can, however, hypothesize that the high proportion of PTSD patients may be due to the proximity of the clinics to a military base. Prevalence of PTSD among veterans is often reported to be greater than the general population, with an estimate that 11 to $20 \%$ of Iraq and Afghanistan veterans suffer from PTSD, whether diagnosed or not, compared to roughly $2 \%$ of the general US population (Ghaffarzadegan et al. 2016). However, the use of cannabis is strictly prohibited among active-duty military and, even among veterans, its use is discouraged (VA and Marijuana - what veterans need to know - Public Health 2020).

In Massachusetts, Maine, Connecticut, and Maryland, over $90 \%$ of patients reported at least one comorbid condition, whereas in Colorado the same was reported by just over $60 \%$ of patients. Among the comorbid conditions reported in the former four states, they were similar to results from a survey that included patients from across the US, Canada, and the UK, where anxiety, back and neck problems, depression, insomnia, chronic pain, stress, and headaches were among the highest reported conditions (Sexton et al. 2016). It is interesting to note that in Connecticut a large number of patients reported comorbid conditions that are not a qualifying condition for the state, demonstrating that although these conditions do not qualify them they are still able to use medical cannabis as a treatment for them as their primary condition is eligible. The same trend is seen within Colorado, but with fewer patients. Patients in Connecticut reported the highest average number of comorbid conditions, and Colorado reported the lowest. We can only speculate here what the source of these differences are between states, but it may be related to the attitudes surrounding medical cannabis, with patients in Colorado not feeling the need to strongly advocate and justify their need for medical cannabis by listing numerous conditions. However, this could also be explained by differing practices for completing assessment appointments between the clinics.

Strengths of this study include the large sample size and detailed information on the patients in these five states. All data collection was verified by a qualified practitioner at the time of input, and thorough information was available on patients' medical conditions. Limitations include missing data on race and gender, a lack of ethnicity information, the use of surrogate income data, and the absence of data on patients who did not qualify for medical cannabis certification and were not included in the registry. Another limitation is that the data came from a single network of clinics and may not be representative of all medical cannabis patients in these states. According to the Marijuana Policy Project website, Massachusetts has 69,008 registered medical cannabis patients (as of March 2020), Colorado has 81, 722 (as of March 2020), Maine has 65,368 (as of December 2019), Connecticut has 41,212 (as of May 2020), and Maryland has 99,912 (as of May 2020). Our largest representation is in Massachusetts at approximately $40 \%$, followed by approximately $20 \%$ in Colorado, $7 \%$ in Maine, 6\% in Connecticut, and 2\% in Maryland (Medical Marijuana Patient Numbers 2021).

\section{Conclusions}

To our knowledge, this study was the first to offer detailed, state-level insights into the characteristics of patients accessing medical cannabis. It highlights the impact of the differing state-eligible qualifying conditions between the five states of Massachusetts, Colorado, Maine, Connecticut, and Maryland and brings into question the routes through which patients choose to seek treatment with cannabis in states where they may not qualify based on their condition. These patients may turn to alternative treatments, or to the illicit or recreational cannabis markets, where permitted. Alternatively, patients may choose to misrepresent their condition to fit in with the regulations in order to gain access to medical cannabis. Patients in these situations may not be granted proper medical oversight or the education needed to increase their chances of success with medical cannabis treatment, which physicians should be aware of.

\section{Abbreviations}

CBD: Cannabidiol; IQR: Interquartile range; IRB: Institutional review board; PTSD: Post-traumatic stress disorder; SD: Standard deviation; THC: $\Delta-9-$ Tetrahydrocannabinol; US: United States

\section{Supplementary Information}

The online version contains supplementary material available at https://doi. org/10.1186/s42238-021-00075-z.

Additional file 1: Figure 1. Patient Flow. Figure 2. Massachusetts Income Distributions. Figure 3. Colorado Income Distributions. Figure 4. Maine Income Distributions. Figure 5. Connecticut Income Distributions. Figure 6. Maryland Income Distributions.

\section{Acknowledgements}

Not applicable.

Authors' contributions

CS and KM conceptualized the study question. AG, CV, and JM completed the analysis and writing of the initial manuscript. CS and KM were integral in interpreting the data and writing and editing the manuscript. The authors read and approved the final manuscript. 


\section{Authors' information}

Not applicable.

\section{Funding}

This study was not funded by any external sources. Authors are employees of CB2 Insights and were compensated as per their contracts for the time to analyze the data and prepare the manuscript.

\section{Availability of data and materials}

The datasets used for this article are not publicly available due to patients' privacy. Data can be made available upon appropriate request to the authors.

\section{Declarations}

\section{Ethics approval and consent to participate}

This research initiative was submitted for IRB review and determined to be exempt from IRB oversight by the Advarra IRB (Pro00042652) as this study had minimal risk, the data exports were void of patient identifiers, and it did not require direct patient contact.

\section{Consent for publication}

Not applicable.

\section{Competing interests}

The authors declare that they have no competing interests aside from being employees of CB2 Insights. All authors contributed to the manuscript as part of an internally guided project. CB2 Insights owns the data, and the authors are all employees of CB2 Insights. No external companies had input on the content of the manuscript, and all data were analyzed in an unbiased fashion. Apart from the authors, CB2 Insights did not play any role in the conduct or analysis of the study, the writing of the manuscript, or the decision to publish.

\section{Received: 21 October 2020 Accepted: 14 May 2021} Published online: 27 May 2021

\section{References}

128th Maine Legislature. An act to amend Maine's medical marijuana law. http:// legislature.maine.gov/legis/bills/getPDF.asp?paper=HP1060\&item $=1 \&$ snum= 128. Accessed 11 Aug 2020.

2018 NSDUH Detailed Tables | CBHSQ Data. https://www.samhsa.gov/data/ report/2018-nsduh-detailed-tables. Accessed 27 Mar 2020.

Alsherbiny MA, Li CG. Medicinal cannabis-potential drug interactions. Med (Basel, Switzerland). 2018;6(1). https://doi.org/10.3390/medicines6010003.

Boehnke KF, Gangopadhyay S, Clauw DJ, Haffajee RL. Qualifying conditions of medical cannabis license holders in the United States. Health Aff. 2019a;38(2): 295-302. https://doi.org/10.1377/hlthaff.2018.05266.

Boehnke KF, Litinas E, Clauw DJ. Medical cannabis use is associated with decreased opiate medication use in a retrospective cross-sectional survey of patients with chronic pain. J Pain. 2016;17(6):739-44. https://doi.org/10.1016/ j.jpain.2016.03.002.

Boehnke KF, Scott JR, Litinas E, Sisley S, Williams DA, Clauw DJ. Pills to pot: observational analyses of cannabis substitution among medical cannabis users with chronic pain. J Pain. 2019b;20(7):830-41. https://doi.org/10.1016/j. jpain.2019.01.010

Bohnert KM, Perron BE, Ashrafioun L, Kleinberg F, Jannausch M, Ilgen MA. Positive posttraumatic stress disorder screens among first-time medical cannabis patients: prevalence and association with other substance use Addict Behav. 2014;39(10):1414-7. https://doi.org/10.1016/j.addbeh.2014.05. 022.

Bureau UC. U.S. Median Household Income Up in 2018 From 2017. https://www. census.gov/library/stories/2019/09/us-median-household-income-up-in-2018from-2017.html. Accessed 25 Mar 2020

Cambron C, Guttmannova K, Fleming CB. State and national contexts in evaluating cannabis laws: a case study of Washington state. J Drug Issues. 2017:47(1):74-90. https://doi.org/10.1177/0022042616678607.

Carliner H, Brown QL, Sarvet AL, Hasin DS. Cannabis use, attitudes, and legal status in the U.S.: a review. Prev Med (Baltim). 2017;104:13-23. https://doi. org/10.1016/j.ypmed.2017.07.008.
Cerdá M, Mauro C, Hamilton A, Levy NS, Santaella-Tenorio J, Hasin D, et al. Association between recreational marijuana legalization in the United States and changes in marijuana use and cannabis use disorder from 2008 to 2016. JAMA Psychiatry. 2020;77(2):165-71. https://doi.org/10.1001/jamapsychiatry.2 019.3254.

Cerdá M, Wall M, Feng T, Keyes KM, Sarvet A, Schulenberg J, et al. Association of state recreational marijuana laws with adolescent marijuana use. JAMA Pediatr. 2017;171(2):142-9. https://doi.org/10.1001/jamapediatrics.2016.3624.

Cerdá M, Wall M, Keyes KM, Galea S, Hasin D. Medical marijuana laws in 50 states: investigating the relationship between state legalization of medical marijuana and marijuana use, abuse and dependence. Drug Alcohol Depend. 2011;120(1-3):22-7. https://doi.org/10.1016/j.drugalcdep.2011.06.011.

Colorado - Official State Web Portal. Qualifying medical conditions Medical Marijuana Registry. https://cdphe.colorado.gov/apply-colorado-medical-ma rijuana-card. Published 2019. Accessed 11 Aug 2020.

Connecticut State Department of Consumer Protection. Qualification Requirements. https://portal.ct.gov/DCP/Medical-Marijuana-Program/Qualifica tion-Requirements. Published 2020. Accessed 11 Aug 2020.

DISA Global Solutions. Map of marijuana legality by state. Retrieved from URL https://disa.com/map-of-marijuana-legality-by-state. 2019.

Eurich DT, Hanlon JG, Boisvenue JJ, Meng H, Dyck JRB. A description of the medical cannabis use in Ontario, Canada. Cannabis Cannabinoid Res. 2019; 4(2):131-5. https://doi.org/10.1089/can.2018.0036.

Fairman BJ. Trends in registered medical marijuana participation across 13 US states and District of Columbia. Drug Alcohol Depend. 2016;159:72-9. https:// doi.org/10.1016/j.drugalcdep.2015.11.015

FDA Regulation of Cannabis and Cannabis-Derived Products, Including Cannabidiol (CBD). U.S. Food and Drug Administration. https://www.fda.gov/ news-events/public-health-focus/fda-regulation-cannabis-and-cannabisderived-products-including-cannabidiol-cbd. Accessed 1 Feb 2020.

Ghaffarzadegan N, Ebrahimvandi A, Jalali MS. A dynamic model of post-traumatic stress disorder for military personnel and veterans. 2016;11(10):e0161405. https://doi.org/10.1371/journal.pone.0161405.

Gorman DM, Huber JC. Do medical cannabis laws encourage cannabis use? Int J Drug Policy. 2007;18(3):160-7. https://doi.org/10.1016/j.drugpo.2006.10.001.

Guzman GG. American Community Survey Briefs. www.census.gov/programs. Accessed 6 Apr 2020.

Legislatures NC of S. State medical marijuana laws. https://www.ncsl.org/resea rch/health/state-medical-marijuana-laws.aspx. 2020.

Leyton M. Cannabis legalization: did we make a mistake? Update 2019. J Psychiatry Neurosci. 2019;44(5):291-3. https://doi.org/10.1503/jpn.190136.

Lucas P, Baron EP, Jikomes N. Medical cannabis patterns of use and substitution for opioids \& other pharmaceutical drugs, alcohol, tobacco, and illicit substances; results from a cross-sectional survey of authorized patients. Harm Reduct J. 2019;16(1):9. https://doi.org/10.1186/s12954-019-0278-6.

Mahabir VK, Merchant JJ, Smith C, Garibaldi A. Medical cannabis use in the United States: a retrospective database study. J Cannabis Res. 2020;2(1):32. https://doi.org/10.1186/s42238-020-00038-w.

Marijuana Decriminalization \& Its Impact on Use - NORML - Working to Reform Marijuana Laws. https://norml.org/aboutmarijuana/item/marijuana-decrimina lization-its-impact-on-use-2. Accessed 9 Apr 2020

Mead A. The legal status of cannabis (marijuana) and cannabidiol (CBD) under U. S. law. Epilepsy Behav. 2017;70:288-91. https://doi.org/10.1016/.yebeh.2016.11.021.

Medical Marijuana Patient Numbers. https://www.mpp.org/issues/medical-marijua na/state-by-state-medical-marijuana-laws/medical-marijuana-patientnumbers/. Accessed 5 Jan 2021.

Natalie M. LaPride - Maryland Medical Cannabis Commission. Patients - who is eligible to register as a patient. https://mmcc.maryland.gov/pages/patients.a spx. Accessed 11 Aug 2020.

Pacula RL, Smart R. Medical marijuana and marijuana legalization. Annu Rev Clin Psychol. 2017;13(1):397-419. https://doi.org/10.1146/annurev-clinpsy-032816045128.

Pertwee RG. Pharmacology of cannabinoid CB1 and CB2 receptors. Pharmacol Ther. 1997;74(2):129-80. https://doi.org/10.1016/s0163-72 58(97)82001-3.

Pertwee RG, Howlett AC, Abood ME, Alexander SPH, di Marzo V, Elphick MR, et al. International Union of Basic and Clinical Pharmacology. LXXIX. Cannabinoid receptors and their ligands: beyond $\mathrm{CB}(1)$ and $C B(2)$. Pharmacol Rev. 2010; 62(4):588-631. https://doi.org/10.1124/pr.110.003004.

Piper BJ, Beals ML, Abess AT, et al. Chronic pain patients' perspectives of medical cannabis; 2017a. https://doi.org/10.1097/j.pain.0000000000000899. 
Piper BJ, Dekeuster RM, Beals ML, et al. Substitution of medical cannabis for pharmaceutical agents for pain, anxiety, and sleep. J Psychopharmacol. 2017b;31(5):569-75. https://doi.org/10.1177/0269881117699616.

Reiman A. Medical cannabis patients: patient profiles and health care utilization patterns. Complement Health Pract Rev. 2007;12(1):31-50. https://doi.org/1 $0.1177 / 1533210107301834$.

Sexton M, Cuttler C, Finnell JS, Mischley LK. A cross-sectional survey of medical cannabis users: patterns of use and perceived efficacy. Cannabis Cannabinoid Res. 2016;1 (1):131-8. https://doi.org/10.1089/can.2016.0007.

Shannon S, Lewis N, Lee H, Hughes S. Cannabidiol in anxiety and sleep: a large case series. Perm J. 2019;23(18-041). https://doi.org/10.7812/TPP/18-041.

The 191st General Court of The Commonwealth of Massachusetts. Chapter 369 An act for the humanitarian medical use of marijuana. https://malegislature. gov/Laws/SessionLaws/Acts/2012/Chapter369. Published 2012. Accessed 11 Aug 2020.

U.S. Census Bureau QuickFacts: United States. https://www.census.gov/quickfacts/ fact/table/CT,CO,MD,ME,MA,US/PST045218. Accessed 9 Apr 2020.

US Income Statistics - Current Census Data for Zip Codes. https://www. incomebyzipcode.com/. Accessed 27 Mar 2020.

VA and Marijuana - what veterans need to know - Public Health. https://www. publichealth.va.gov/marijuana.asp. Accessed 22 Apr 2020.

\section{Publisher's Note}

Springer Nature remains neutral with regard to jurisdictional claims in published maps and institutional affiliations.

Ready to submit your research? Choose BMC and benefit from:

- fast, convenient online submission

- thorough peer review by experienced researchers in your field

- rapid publication on acceptance

- support for research data, including large and complex data types

- gold Open Access which fosters wider collaboration and increased citations

- maximum visibility for your research: over $100 \mathrm{M}$ website views per year

At $\mathrm{BMC}$, research is always in progress.

Learn more biomedcentral.com/submissions 